\title{
Relationship between Climate Change and Agricultural Development Transition
}

\author{
Yanni LIU* and Jingrun SU \\ Northwest University, Xi'an, China; lyn@nwu.edu.cn; 201920082@stumail.nwu.edu.cn \\ * Corresponding author: lyn@nwu.edu.cn
}

\begin{abstract}
Extensive agricultural development mode increases the climate problem caused by carbon emissions, thus restricting the development of agricultural economy. Under this background, this paper studies the relationship between climate change and the transformation of agricultural development mode from the perspective of carbon emissions and agricultural total factor productivity (TFP). Based on the Regional Panel Data of 1995-2016, this paper uses the co-integration model and error correction model to explore the impact of long-term and short-term carbon emissions on agricultural TFP, and further analyzes the impact mechanism. The research shows that carbon emissions from diesel fuel, irrigation and pesticide for agriculture mainly restrain agricultural TFP by restraining agricultural technology efficiency (TEC) in the long and short term; agricultural film carbon emissions only have the same effect in the short term; in the short term, carbon emission of agricultural machinery restrains agricultural TFP by restraining TP. In the long and short term, fertilizer carbon emissions will promote the growth of agricultural TFP by improving TEC. There is a short-term reverse correction mechanism between them, and the short-term deviation will recover more quickly. This paper puts forward suggestions on low-carbon circular agriculture, adjustment of agricultural production structure and promotion of agricultural modernization.
\end{abstract}

Keywords: carbon emission; agricultural total factor productivity; co-integration model; error correction model

\section{JEL Classification: Q54}

\section{Introduction}

The issue of climate change is accompanied by the way of human development. It is a necessary product of mankind's transformation of nature and social activities. In turn, climate change will also affect and restrict the way of human development. Especially agriculture is very sensitive to climate change, so it is vulnerable to the potential impact of changes in climate conditions. The production methods in the process of agricultural development are one of the important reasons for climate change. Extensive farming methods, excessive use of agricultural industrial products such as chemical fertilizers and pesticides, and the abuse of agricultural energy caused by "modern agriculture" all emit large amounts of greenhouse gases. The increase of greenhouse gas emissions, such as methane, nitrogen oxides and carbon dioxide, gradually accumulates from quantity to quality, affecting the global climate change. Climate changes such as rising temperatures, changes in precipitation, changes in glaciers, and extreme weather will restrict the high-quality growth of the agricultural economy by affecting the 
layout of the agricultural planting industry, and the output and quality of agricultural products. To improve the impact of climate change, the fundamental way to achieve highquality development of agricultural economy lies in the transformation of agricultural development methods. The transformation of the agricultural development model means the transformation from extensive to intensive, from quantitative to qualitative, and transforms agricultural economic growth from an increase in factor input to an increase in agricultural total factor productivity. Therefore, to study the relationship between climate change and the transformation of agricultural development mode, we must first study the relationship between agricultural carbon emissions and agricultural total factor productivity.

Agricultural TFP has been widely concerned by scholars at home and abroad. They use different measurement methods to analyze the TFP and its influencing factors of different regions and varieties of crops (Mead, 2003; Wen, 1993; Chen, Ma, Che et al., 2020). The calculation methods of agricultural total factor productivity can be divided into Solow residual method, non-parametric data envelope analysis and typical SFA stochastic frontier production model. On the basis of C-D production function, Solow (1957) proposed that capital, labor and technical efficiency are the driving forces of economic growth, and constructed CES production function. On this basis, some scholars use the Solow residual method and its extended model to calculate the total factor productivity (Huilong \& Lei, 2018; Schultz \& Abramovitz, 1956). However, it has strong constraints, Hicks neutrality and constant returns to scale. It ignores the existence of technical efficiency, only regards the total factor growth rate as the result of technological progress. Due to the strong uncertainty of natural factors such as climate change, some scholars use stochastic production frontier function to measure agricultural TFP (Liu \& Zhang, 2017; Brümmer et al., 2006; Kumbhakar \& Lovell, 2000). This method considers the influence of random factors, which is more in line with the background of climate change. The advantage of nonparametric data envelopment analysis is that it does not need to determine the specific production function and is not affected by the dimension of input-output variables. It is suitable for the calculation of a large amount of data. The DEA method originates from the analysis of Farrell (1957). Through the development of Charnes (1978), a more mature analysis paradigm has been formed. Tone (2002) systematically explains such methods. This method is applied to the calculation of TFP (Liu et al., 2016; Coelli \& Rao, 2003; Fare et al., 1994).

Climate change is an important factor affecting agricultural TFP. Zhong and Jiang (2019) believe that factors such as annual total precipitation, mean temperature in growing season, and evaporation intensity have significant negative effects on regional agricultural total factor productivity. Jin and Kan (2013) found that natural disasters in the agricultural production environment can restrain agricultural TFP by affecting technological progress. Based on the perspective of carbon emissions, the literature studying the impact of climate change on agricultural development mode mainly includes agricultural carbon emissions as an unexpected output into the productivity calculation, so as to obtain agricultural green productivity, and then compare with the traditional agricultural total factor productivity. Scholars have found that environmental pollutants such as agricultural carbon emissions can inhibit agricultural total factor productivity, and the path of impact includes technological progress and technical efficiency (Wang et al., 2019; Zhan et al., 2019; Pan Dan, 2014). Climate 
change and agricultural development is a two-way interactive mechanism. The relationship between economic development and carbon emissions presents an inverted $U$ curve. With the increase of production investment, carbon emissions increased. When the economy develops to a certain scale, high-quality economic development model will inhibit agricultural carbon emissions (Li et al., 2011; Zhang et al., 2014). Xu and Song (2010) obtained the same effect in central and eastern China by using the Co-integration Model. The Co-integration Model reflects the long-term stable relationship between variables. Zhao and $\mathrm{Li}$ (2011) used the Co-integration Model to find that economic growth will bring about an increase in carbon emissions, and an increase in carbon emissions will also bring about economic growth.

There are still the following deficiencies, agricultural carbon emissions include agricultural planting and animal husbandry and other carbon emissions. Greenhouse gases are emitted from chemical fertilizer, pesticide, agricultural film, machinery, irrigation and other carbon sources in agricultural planting industry. However, the existing literature does not discuss the impact of specific carbon emissions on agricultural total factor productivity and the path. On the other hand, high quality agricultural development will inhibit agricultural carbon emissions. Climate change and agricultural development mode is a two-way interaction mechanism. So this paper uses the Co-integration Model to study the long-term relationship between climate change and the transformation of agricultural development mode, and uses the error correction model to explore the short-term impact. In view of this, this paper intends to build a Co-integration Model of carbon emissions from various carbon sources of agricultural planting industry and agricultural total factor productivity and analyze the impact of carbon emissions from various carbon sources on agricultural total factor productivity for a long time and the impact path. If there is a long-term equilibrium relationship, build a Vector Error Correction Model to study whether there is any deviation in the short-term and the correction speed to restore to the long-term equilibrium.

Huang and Mi (2011) divided the sources of carbon emissions from agricultural production into five parts: agricultural industrial products input, agricultural energy, planting emissions, aquaculture emissions and organic waste. By quantifying the agricultural carbon footprint, they found that the most important carbon emissions are from the industrial products (chemical fertilizer, pesticide, agricultural film, etc.) input in the agricultural production process and the use of agricultural energy. Therefore, in order to study the impact of agricultural carbon emissions on agricultural total factor productivity, it is necessary to analyze the input of agricultural industrial products and the carbon emissions of agricultural energy. Due to the impact of traditional "agricultural modernization", farmers only care about output but not quality, which will deepen the mechanization and chemistry of agricultural production. In the process of mechanization, it is inevitable to increase agricultural energy consumption such as electricity, oil and coal, and increase carbon emissions. On the other hand, the production, use and treatment of chemical fertilizer, pesticide and agricultural film will directly or indirectly generate carbon emissions. Ammonia will escape into the atmosphere during the application of chemical fertilizer, followed by the nitration and denitrification process of nitrogen in the soil, which will produce greenhouse gases. In addition, due to the extensive use of chemical fertilizer, the natural properties of the soil have been changed and the process of 
carbon emission has been accelerated. The use of pesticide such as weedicide, pesticide, and fungicide will also change the respiratory rate of crops and other factors to increase greenhouse gas emissions. In order to protect the seedlings, the agricultural land needs to be covered with film before the crops are planted, the residual agricultural film will change the nature and structure of the soil, thus accelerating carbon emissions. The increase of agricultural carbon emissions has brought about climate changes such as temperature rise, precipitation change and natural disasters caused by greenhouse effect. Agricultural production is more sensitive to the impact of climate change, so the increase in carbon emissions caused by climate change will certainly have a certain impact on the agricultural economy. The increase of carbon emissions from various carbon sources has positive and negative effects on the agricultural economy. On the one hand, the increase of carbon emission from agricultural sources means the deepening of agricultural mechanization and chemistry, which will undoubtedly promote economic growth. On the other hand, the increase in carbon emissions has also intensified the climate change caused by environmental pollution, thus affecting agricultural production. From the perspective of positive effects of agricultural carbon emissions. The use of agricultural machinery can improve the production efficiency of farmers, and the use of chemical fertilizer, pesticide and agricultural film can protect the growth and development of crops. With the continuous improvement of technology, the research and development of new equipment and the upgrading of agricultural industrial inputs can improve the total factor productivity of agriculture by promoting technological progress. The negative effect of agricultural carbon emissions is reflected in the fact that climate change will affect agricultural total factor productivity by affecting agricultural planting systems, regions, types of crops and agricultural production habits. Therefore, the increase of agricultural carbon emissions has positive and negative effects. It is of great significance to quantify the positive and negative effects of specific carbon source emissions and analyze the impact path to understand the impact of climate change on agricultural development.

\section{Methodology}

This paper calculates agricultural carbon emissions by using the input of key elements in national agricultural planting production, and then uses the co-integration model to analyze the long-term and short-term relationship between agricultural total factor productivity and carbon emissions from various agricultural carbon sources.

\subsection{Calculation Method of Agricultural Carbon Emission}

Agricultural carbon emissions are greenhouse gases formed in the process of agricultural production activities, including carbon emissions caused by the use of pesticide in agricultural production; the production of fertilizer and fertilizer; the production of agricultural film and membrane; the inflow of organic carbon in the soil into the air during the ploughing and diesel fuel consumed during the mechanized production. Computing formula:

$$
E=\sum E_{i}=\sum T_{i} * \delta_{i}
$$


where represents the total amount of carbon emissions, $\sum E_{i}$ represents the sum of carbon emissions from different source, $T_{i}$ represents the amount of various carbon sources, $\delta_{i}$ represents the corresponding emission coefficient of various carbon sources. According to the relevant literature (IREEA, 2016; ORNL, 2016; Li et al., 2011; IPCC, 2006; West \& Marland, 2002), the coefficients of different agricultural carbon sources are shown in Table 1 :

Table 1. Carbon emission sources and factor

\begin{tabular}{cccc}
\hline sources & factor & sources & factor \\
\hline chemical fertilizer & $0.8956 \mathrm{~kg} \mathrm{c} / \mathrm{kg}$ & diesel oil & $0.5927 \mathrm{~kg} \mathrm{c} / \mathrm{kg}$ \\
pesticide & $4.9341 \mathrm{~kg} \mathrm{c} / \mathrm{kg}$ & irrigation & $266.48 \mathrm{~kg} \mathrm{c} / \mathrm{hm} 2$ \\
agricultural film & $5.18 \mathrm{~kg} \mathrm{c} / \mathrm{kg}$ & & \\
\hline
\end{tabular}

The calculation of carbon emission from agricultural machinery is based on the calculation formula: $E e=A e{ }^{*} D+W e{ }^{*} F$, where $A e$ representative planting area, We represents the total power of agricultural machinery $\mathrm{D}=16.47 \mathrm{~kg} \mathrm{c} / \mathrm{hm} 2, \mathrm{~F}=0.18 \mathrm{~kg} \mathrm{c} / \mathrm{kW}$. In this paper, carbon dioxide emission is used as a variable to measure carbon emissions. According to the mass balance method, the formula for converting carbon into carbon dioxide is: $\mathrm{CO}_{2}=c \times \frac{44}{12}$.

\subsection{Co-integration Model and Vector Error Correction Model}

Cointegration test, also known as EG cointegration test. In 1987, Engle and Granger proposed to determine whether there is a long-term equilibrium relationship between unstable sequences. Definition of Cointegration Relation: Set the random sequence $x_{i}$ to contain only components of order D single integers, record as $x_{i} \sim I(d)$. Assume there is a non-zero vector $\beta$ can satisfy random vector $Y_{i}=\beta x_{i} \sim I(d, b)$, we can say that $x_{i}$ is b,d order cointegration, record as $x_{i} \sim C I(d, b), \beta$ is cointegration vector. In particular, $Y_{i}$ and $x_{i}$ are random variables, $Y_{i}, x_{i} \sim I(1), Y_{i}=k_{0}+k_{1} x_{i} \sim I(0)$, then called $Y_{i}, x_{i}$ arecointegrated, $k_{0} 、 k_{1}$ is the co-integration coefficient.

It seems that there is a long-term equilibrium among some variables obtained through the co integration test, but it is not the case. It is also normal for some variables with stable co-integration relationship to fail to reach the equilibrium in the short term. Therefore, we need to use error correction model to make up for this defect. The specific method of error correction model is to combine the short-term relationship with the long-term and mediumterm data and correct the part that cannot reach the equilibrium state. It can be defined as: assuming that $\mathrm{x}$ and $\mathrm{y}$ are single integral sequences of the same order, if there is a cointegration relationship between $x$ and $y$, we can use the Vector Error Correction Model to reflect this short-term relationship:

$$
\begin{gathered}
y_{t}=a+\delta_{1} y_{t-1}+\beta_{0} x_{t}+\beta_{1} x_{t-1}+u_{t} \\
\Delta y_{t}=a-\left(1-\delta_{1}\right) y_{t-1}+\beta_{0} \Delta x_{t}+\left(\beta_{0}+\beta_{1}\right) x_{t-1}+u_{t} \\
\Delta y_{t}=\beta_{0} \Delta x_{t}-\left(1-\delta_{1}\right)\left(y_{t-1}-k_{0}-k_{1} x_{t-1}\right)+u_{t}
\end{gathered}
$$


$k_{0}=\frac{\alpha}{1-\delta_{1}}, k_{1}=\frac{\beta_{0}+\beta_{1}}{1-\delta_{1}}$, Formula (4) is called first order error correction model. $\beta_{0}$ is the influence parameter; $\left(1-\delta_{1}\right)$ is feedback effect; $k_{0}, k_{1}$ is the long-term reflection coefficient. It is not difficult to see that the specific approach of the model will separate the short-term impact from the long-term impact in the explained variables, and then clearly and intuitively reflect how the short-term fluctuations affect the co integration relationship between different variables. Therefore, the co-integration theory and error correction model not only help us in the selection of variables, but also help us to determine the relationship between variables.

\subsection{Data Source and Variable Selection}

Based on previous literature studies and considering the requirements of sample availability and timeliness, the panel data variables of China from 1995 to 2016 are selected as follows.

Dependent variables. Total Factor Productivity of Agriculture (TFP), Technical efficiency index (TEC), Technology progress index (TP). Wang Junyang and Xiuyun (2019) use the classic non parameter DEA-Malmquist index to calculate the national and sub regional agricultural TFP, technical efficiency index (TEC) and technical progress index (TP) through the added value of the first industry, the number of employees in the first industry, the planting area of crops, the converted net amount of chemical fertilizer and the total power of agricultural machinery. This paper refers to their calculated results.

Core explanatory variables. Carbon dioxide emissions from inputs of various elements in agricultural production activities, including Carbon emission of chemical fertilizer (fertilizerp), Carbon emissions of pesticides (pesticidep), Carbon emission of agricultural plastic film (filmp), Mechanical carbon emissions (machinep), Carbon emission of diesel oil (Oilp) and Carbon emissions of agricultural irrigation (irrp). The calculation of carbon emission is based on such indexes as total power of agricultural machinery $/ 10,000 \mathrm{~kW}$, plastic film usage for agriculture/ton, diesel oil usage for agriculture/10,000 tons, pesticide usage/10,000 tons, effective irrigation area/1,000 hectares, and purified fertilizer application for agriculture $/ 10,000$ tons. Calculate the carbon emissions by 2.1 .

Control Variables. According to the previous literature research, the following variables that have an impact on agricultural TFP are selected as the control variables. The fixed asset investment amount of rural households/billion yuan (fi) and the number of employees in agriculture, forestry, animal husbandry and fishery/10,000 (labor), these 2 indicators reflect the level of capital and labor input in agricultural production in various regions. Industry, this indicator is measured by the ratio of industrial added value of each region to the regional GDP. The larger the ratio, the higher the degree of industrialization. The level of open(open) is measured by the number of foreign-invested enterprises in each region. Agricultural electricity (electricity), which is measured by rural electricity consumption per 100 million kwh, also affects the total factor productivity of agriculture.

The above data are from China research data service platform (CNRDS) Regional Economic Research (CRED), China Statistical Yearbook and China Rural Statistical Yearbook. In order to eliminate the effect of the variance, we carry out natural logarithm transformation 
on the absolute variables such as open, electricity, fi, labor, pesticidep, Oilp, irrp, filmp, fertilizerp and machinep, and standardize the independent variables to eliminate the dimensional effect.

\section{Results}

This paper attempts to study the relationship between agricultural carbon emissions and total factor productivity by building a long-term Co-integration Model. This requires first performing the unit root (ADF) test of each variable and then the cointegration test to determine the long-term relationship model between each variable on the premise that each component has the same order sequence. Since TFP is also affected by short-term fluctuations in carbon emissions, Vector Error Correction Model need to be constructed to determine whether corrective mechanisms exist.

\subsection{Panel Unit Root Test for Each Variable}

Only when the variables introduced into the model reach the same level of single integration, the co-integration test can be carried out. We used LLC test (2002), IPS test (2003) and Breitung test $(2000,2005)$ to conduct panel unit root test for each variable. The original assumption of the tests is that the variable has unit root process and belongs to non-stationary series. The reserve assumption of IPS test is that a certain proportion of individuals are stationary series, while the reserve assumption of LLC test (2002) and Breitung test is that all individuals are stationary series. For the 3 results, whether the variable is stable is judged by voting. The test result with the largest number of votes is the final result. The specific inspection results are shown in Table 2.

Table 2. Panel stability test result

\begin{tabular}{ccccccc}
\hline \multirow{2}{*}{ Variable } & \multicolumn{3}{c}{ Original sequence } & \multicolumn{3}{c}{ First difference series } \\
\cline { 2 - 6 } & LLC & IPS & Breitung & LLC & IPS & Breitung \\
lnopen & 1.9682 & 0.6407 & -0.7571 & $-4.3181^{* * *}$ & $-3.6620^{* * *}$ & $-1.9901^{* *}$ \\
Inelectricity & 0.8958 & 1.6204 & -1.2208 & $-6.9916^{* * *}$ & $-6.3356^{* * *}$ & $-1.8349^{* *}$ \\
lnfi & 0.9136 & 0.3691 & 1.5001 & $-9.3840^{* * *}$ & $-6.9165^{* * *}$ & -1.0029 \\
lnlabor & 0.7362 & 2.2085 & -0.2578 & $-5.9556^{* * *}$ & $-7.4676^{* * *}$ & $-1.6789^{* *}$ \\
industry & 0.2128 & 0.9157 & 1.2514 & $-6.6757^{* * *}$ & $-7.5598^{* * *}$ & -0.4483 \\
lnpesticidep & 0.7142 & 2.9601 & 1.2520 & $-8.8024^{* * *}$ & $-8.9973^{* * *}$ & $-1.7801^{* *}$ \\
lnoilp & 1.3158 & 1.1584 & -0.4711 & $-6.1860^{* * *}$ & $-5.3366^{* * *}$ & $-2.0663^{* *}$ \\
lnirrp & $-2.7952^{* * *}$ & -0.3711 & 2.1530 & $-5.4343^{* * *}$ & $-4.7845^{* * *}$ & $-2.7195^{* * *}$ \\
lnfilmp & 0.5435 & -0.2644 & -0.1712 & $-5.5707^{* * *}$ & $-7.0388^{* * *}$ & $-2.0935^{* *}$ \\
lnfertilizerp & 4.5421 & 0.4799 & 0.2300 & $-4.9664^{* * *}$ & $-6.5711^{* * *}$ & $-1.5922^{*}$ \\
lnmachinep & 1.7261 & 2.3316 & 1.7233 & $-4.4988^{* * *}$ & $-4.7558^{* * *}$ & $-1.8035^{* *}$ \\
tfp & $-4.4850^{* * *}$ & -0.7685 & 1.2260 & $-13.4825^{* * *}$ & $-12.5275^{* * *}$ & $-4.7837^{* * *}$ \\
tp & -1.3097 & $-5.3469^{* * *}$ & -0.2947 & $-12.6374^{* * *}$ & $-11.7734^{* * *}$ & $-3.6708^{* * *}$ \\
tec & -0.5929 & $-1.5927^{*}$ & 0.4241 & $-5.4496^{* * *}$ & $-9.9811^{* * *}$ & $-3.7761^{* * *}$ \\
\hline
\end{tabular}

${ }^{2}$ The superscript ${ }^{* * *},{ }^{* *},{ }^{*}$ are significant at the level of $1 \%, 5 \%$, and $10 \%$, respectively.

To sum up, the original sequence of each variable is not stationary, while their first-order difference sequence is stationary. Each variable is integrated of order one, i.e. the I (1) process. Since each sequence belongs to the same order single integer sequence, we can perform longterm co-integration analysis between variables. 


\subsection{Cointegration Test for Total Samples}

This paper uses Kao test $(1999)$ and Pedroni test $(1999,2004)$ to test whether there is a long-term cointegration relationship between variables. Both of these methods are panel cointegration tests based on residuals and assume that the sections are independent. The original assumption of both methods is that there is no co-integration relationship for all individuals, while the alternative assumption is that there is co-integration relationship for all individuals. This paper tests the long-term cointegration relationship between different variables by six types of cointegration relationships. Dependent variables tfp, tp, tec and core explanatory variables lnpesticidep, lnoilp, lnirrp, lnfilmp, lnfertilizerp and lnmachinep form model 1, model 2 and model 3 respectively. Dependent variables tfp, tp, tec and core explanatory variables and control variables lnopen, lnelectricity, lnfi, lnlabor, industry constitute model 4 , model 5 and model 6 respectively. The inspection results are shown in Table 3 below.

Table 3. Panel cointegration test results

\begin{tabular}{|c|c|c|c|c|c|c|}
\hline Statistic & Model 1 & Model 2 & Model 3 & Model 4 & Model 5 & Model 6 \\
\hline Kao test & $-5.8875^{* * *}$ & $-3.8026^{* * *}$ & $-9.2822^{* * *}$ & $-5.6898^{* * *}$ & $-3.6459^{* * *}$ & $-9.3964^{* * *}$ \\
\hline DF value & $(0.0000)$ & $(0.0001)$ & $(0.0000)$ & $(0.0000)$ & $(0.0001)$ & $(0.0000)$ \\
\hline \multicolumn{7}{|l|}{ Pedroni test } \\
\hline Panel v & $\begin{array}{c}-2.4821^{* * *} \\
(0.0065)\end{array}$ & $\begin{array}{l}-2.5968^{* * *} \\
(0.0047)\end{array}$ & $\begin{array}{c}-2.5312^{* * *} \\
(0.0057)\end{array}$ & - & - & - \\
\hline Panel rho & $\begin{array}{c}1.0074 \\
(0.1569)\end{array}$ & $\begin{array}{c}0.1497 \\
(0.4405)\end{array}$ & $\begin{array}{c}0.5281 \\
(0.2987)\end{array}$ & - & - & - \\
\hline Panel pp & $\begin{array}{c}-7.5448^{* * *} \\
(0.0000)\end{array}$ & $\begin{array}{l}-8.3155^{* * *} \\
(0.0000)\end{array}$ & $\begin{array}{c}-7.0675^{* * *} \\
(0.0000)\end{array}$ & - & - & - \\
\hline Panel ADF & $\begin{array}{c}-1.360 \mathrm{e}+15^{* * *} \\
(0.0000)\end{array}$ & $\begin{array}{l}-8.9155^{* * *} \\
(0.0000)\end{array}$ & $\begin{array}{c}-5.4093^{* * *} \\
(0.0000)\end{array}$ & - & - & - \\
\hline Group rho & $\begin{array}{l}1.8463^{* *} \\
(0.0324)\end{array}$ & $\begin{array}{c}0.9025 \\
(0.1834)\end{array}$ & $\begin{array}{c}1.2624 \\
(0.1034)\end{array}$ & - & - & - \\
\hline Group pp & $\begin{array}{c}-8.4454^{* * *} \\
(0.0000)\end{array}$ & $\begin{array}{c}-10.0927^{* * *} \\
(0.0000)\end{array}$ & $\begin{array}{c}-9.2630^{* * *} \\
(0.0000)\end{array}$ & - & - & - \\
\hline Group ADF & $\begin{array}{c}-4.599 \mathrm{e}+15^{* * *} \\
(0.0000)\end{array}$ & $\begin{array}{c}-11.0363^{* * *} \\
(0.0000)\end{array}$ & $\begin{array}{c}-6.1461^{* * *} \\
(0.0000)\end{array}$ & - & - & - \\
\hline
\end{tabular}

${ }^{3}$ The superscript ${ }^{* * *},{ }^{* *},{ }^{*}$ are significant at the level of $1 \%, 5 \%$, and $10 \%$, respectively. The p-value is in brackets.

In the case of small samples, group ADF and panel ADF are the best in pedroni test. Due to the limitation of data, there are too many variables in the model after adding control variables, so pedroni test cannot be carried out. Therefore, the values of seven statistics in pedroni test of model 4, model 5 and Model 6 are not listed in the table. According to the results of Kao test, we reject the hypothesis that there is no co integration relationship at the significance level of $1 \%$. Therefore, we can also think that the variables in model 4 , model 5 and Model 6 with control variables have cointegration relationship. In summary, the six models have been tested by Kao test and pedroni test, and the original hypothesis that there is no co integration relationship is rejected. We think that there is co integration relationship among variables in each model. 


\subsection{The Residual-Based Panel Fully Modified OLS (FMOLS)}

After determining that there is a co-integration relationship between variables, we used FMOLS for co-integration regression. Compared with OLS estimation method, FMOLS estimation can better solve the problems of endogeneity of variables and biased estimation results. Dependent variables $\mathrm{tfp}$, tp, tec and core explanatory variables and control variables lnopen, lnelectricity, lnfi, lnlabor, industry constitute model 4, model 5 and model 6 respectively. The estimated results are shown in Table 4.

Table 4. FMOLS regression results

\begin{tabular}{cccc}
\hline Explanatory variables & Model 4 & Model 5 & Model 6 \\
\hline lnfilmp & 0.006419 & 0.035371 & -0.027437 \\
& $(0.475686)$ & $(1.421778)$ & $(-0.984457)$ \\
lnoilp & $-0.042155^{* * *}$ & $0.099332^{* * *}$ & $-0.136897^{* * * *}$ \\
& $(-3.690655)$ & $(4.311886)$ & $(-5.384061)$ \\
lnmachinep & -0.002718 & -0.023887 & 0.031494 \\
& $(-0.134199)$ & $(-0.723819)$ & $(0.839363)$ \\
lnirrp & $-0.232587^{* * *}$ & 0.022899 & $-0.242263^{* * *}$ \\
& $(-9.602969)$ & $(0.579870)$ & $(-5.339365)$ \\
lnfertilizerp & $0.110299^{* * *}$ & $-0.146511^{* *}$ & $0.274641^{* * *}$ \\
lnpesticidep & $(2.961456)$ & $(-2.602231)$ & $(4.280323)$ \\
Control Variables & $-0.104460^{* * *}$ & $0.162924^{* * *}$ & $-0.263281^{* * *}$ \\
R2 & $(-5.717707)$ & $(5.433335)$ & $(-7.711458)$ \\
& YES & YES & YES \\
\hline
\end{tabular}

${ }^{4}$ The superscript ${ }^{* * *},{ }^{* *},{ }^{*}$ are significant at the level of $1 \%, 5 \%$, and $10 \%$, respectively. The $\mathrm{t}$-statistic is in brackets.

We can find that the carbon emission of agricultural film has no significant effect on the improvement of TFP. As the first largest carbon source of agricultural carbon emissions, chemical fertilizer has made great contribution to the growth of agriculture in China. However, excessive use of chemical fertilizer will also cause pollution. The coefficient of lnfertilizerp is 0.110299 , which is significant at a significant level of $1 \%$, indicating that the carbon emission of fertilizer increases by $1 \%$, and the agricultural TFP increases by 0.110299 units. In addition, the carbon emissions from the other 4 carbon sources will inhibit the growth of agricultural TFP. The effect of carbon emission from agricultural machinery (lnmachinep) is not significant. The coefficient of lnoilp, lnirrp, lnpesticidep are -0.042155 , $-0.232587,-0.104460$, respectively, which is significant at a significant level of $1 \%$. Its carbon emission increased by $1 \%$, the agricultural TFP decreased by 0.042155 units, 0.232587 units, 0.104460 units, respectively. Agricultural irrigation, as the second largest carbon source of agricultural carbon emissions, its growth trend is still rising, and has seriously affected the improvement of agricultural total factor productivity. How to solve the problem of irrigation emission reduction is the focus of current research.

In order to further analyze the path of each carbon source affecting agricultural total factor productivity, this paper respectively constructs model 5 and Model 6 with agricultural technology progress (tp), agricultural technology efficiency (tec) and core explanatory variables and control variables. The results are as follows: 
Model 5 reflects the impact of carbon emissions from various carbon sources of agricultural production on agricultural technological progress (TP). The coefficient values of lnpesticidep and lnoilp are 0.162924 and 0.099332, respectively, which are significant at a significant level of $1 \%$, indicating that their carbon emissions increased by $1 \%$, and the agricultural TP increased by 0.162924 and 0.099332 units, respectively. The coefficient of carbon emission from fertilizer (lnfertilizerp) is -0.146511 , which is significant at a significant level of $5 \%$. It increases by $1 \%$, and the agricultural TP will decrease by 0.146511 units. Lnfilmp and lnirrp did not significantly promote the agricultural TP. The inhibition of agricultural machinery carbon emission (lnmachinep) was not significant.

Model 6 reflects the impact of carbon emissions from various carbon sources of agricultural production on agricultural technical efficiency (TEC). The coefficient values of lnpesticidep, lnoilp, lnirrp and lnfertilizerp are $-0.263281,-0.136897,-0.242263$ and 0.274641 , respectively, which are significant at the significant level of $1 \%$. Inhibitory effect of lnfilmp on TEC is not significant. lnmachinep do not significantly promote technical efficiency. This indicated that the lnpesticidep, lnoilp, lnirrp could significantly inhibit the agricultural TEC, which increased by $1 \%$ and reduced the agricultural technical efficiency by $0.263281,0.136897$ and 0.242263 units respectively. Lnfertilizerp will have a significant positive effect on agricultural technology efficiency, which will increase by $1 \%$ and agricultural TEC increase by 0.274641 units.

In summary, in the long run, there are positive and negative effects of carbon emissions from various carbon sources on agricultural TFP, and they can be divided into technological progress and technological efficiency. Agricultural film carbon emissions and agricultural machinery carbon emissions have no significant impact on agricultural TFP, TP, TEC for a long time. Agricultural diesel carbon emissions, agricultural irrigation carbon emissions, and pesticide carbon emissions mainly restrain agricultural TFP by restraining agricultural TEC, while their promotion to agricultural TP slows down the degree of restraint. However, carbon emissions from agricultural irrigation did not significantly promote $\mathrm{TP}$, which also led to the greatest inhibition on agricultural TFP. Chemical fertilizer carbon emission mainly promotes agricultural TFP by promoting agricultural TEC, while its inhibition on TP reduces the degree of promotion.

\subsection{Vector Error Correction Model}

The long-term equilibrium relationship between agricultural TFP and carbon sources of agricultural production is reflected by the previous Co-integration Model. How to correct short-term fluctuations around the long-term equilibrium relationship needs to be achieved by establishing the Vector Error Correction Model. In this paper, the regression residuals (ecm) of model 4, model 5 and Model 6 are calculated according to the three co-integration regression equations. The first-order difference sequence of agricultural TFP, TP, TEC and the first-order difference sequence of each agricultural carbon source carbon emission and control variable as well as the regression residual $(\mathrm{ecm})$ constitute error correction models 7 , 8 and 9. The model regression results are shown in Table 5 below. 
Table 5. Error Correction Model regression results

\begin{tabular}{|c|c|c|c|}
\hline \multirow{2}{*}{ Explanatory variables } & Model 7 & Model 8 & Model 9 \\
\hline & $\Delta(\mathrm{tfp})$ & $\Delta(\mathrm{tp})$ & $\Delta($ tec $)$ \\
\hline \multirow{2}{*}{$\Delta(\mathrm{Yt}-1)$} & 0.084375 & $0.274609^{* * *}$ & $0.254149^{* * *}$ \\
\hline & (1.531608) & (15.68571) & (13.30265) \\
\hline \multirow{2}{*}{$\triangle(\operatorname{lnfilmp})$} & -0.007760 & $0.169190^{* * *}$ & $-0.193812^{* * *}$ \\
\hline & $(-0.443973)$ & (11.27335) & $(-12.86921)$ \\
\hline \multirow{2}{*}{$\Delta($ lnoilp $)$} & $-0.088953^{* * *}$ & $0.037398^{* * *}$ & $-0.109907^{* * *}$ \\
\hline & $(-8.282938)$ & $(3.988770)$ & $(-11.04025)$ \\
\hline \multirow{2}{*}{$\triangle($ lnmachinep $)$} & $-0.049073^{* *}$ & $-0.071263^{* * *}$ & $0.040485^{* * *}$ \\
\hline & $(-2.568566)$ & $(-5.323341)$ & $(2.908704)$ \\
\hline \multirow{2}{*}{$\Delta($ lnirrp $)$} & $-0.243873^{* * *}$ & $0.075005^{* * *}$ & $-0.306101^{* * *}$ \\
\hline & $(-8.349004)$ & $(4.042169)$ & $(-14.84638)$ \\
\hline \multirow{2}{*}{$\triangle($ lnfertilizerp $)$} & $0.178028^{* * *}$ & $-0.371455^{* * *}$ & $0.568451^{* * *}$ \\
\hline & $(5.328472)$ & $(-17.06731)$ & $(27.34397)$ \\
\hline \multirow{2}{*}{$\triangle($ lnpesticidep $)$} & $-0.103922^{* * *}$ & $0.132566^{* * *}$ & $-0.232114^{* * *}$ \\
\hline & $(-6.634281)$ & $(12.69320)$ & $(-20.39417)$ \\
\hline \multirow{2}{*}{ ecm $(-1)$} & $-1.391406^{* * *}$ & $-1.593920^{* * *}$ & $-1.577293^{* * *}$ \\
\hline & $(-14.49810)$ & $(-54.32370)$ & $(-49.65659)$ \\
\hline Control Variables & YES & YES & YES \\
\hline $\mathrm{R} 2$ & 0.684020 & 0.732803 & 0.706428 \\
\hline
\end{tabular}

${ }^{5}$ The superscript ${ }^{* * *},{ }^{* *},{ }^{*}$ are significant at the level of $1 \%, 5 \%$, and $10 \%$, respectively. The $\mathrm{t}$-statistic is in brackets. $\mathrm{Y}$ is dependent variables.

The error correction term coefficients of model 7, model 8 and model 9 are -1.391406, 1.593920 and -1.577293 , which are significant at the $1 \%$ significant level. It indicates that in the long-term equilibrium process of agricultural TFP, TP, TEC and carbon emissions from various carbon sources, if there is deviation fluctuation in a short time, it will deviate back to the equilibrium level with strong regulation efficiency, which is in line with the reverse correction mechanism.

From the short-term effect analysis, except in Model 7, the carbon emission coefficient of agricultural film is not significant, the carbon emission coefficient of machinery is significant at a significant level of $5 \%$, the other core explanatory variables are significant at a significant level of $1 \%$. The results show that in the short term, agricultural film carbon emissions, agricultural diesel emissions, agricultural irrigation carbon emissions, and pesticide carbon emissions will inhibit agricultural TFP by suppressing agricultural TEC, while its promotion on TP will slow down this effect. However, compared with the inhibition, the carbon emission of agricultural film has a greater promotion on TP, so its inhibition on agricultural TFP is not significant. Agricultural machinery carbon emissions can inhibit agricultural TFP by inhibiting TP, while the improvement of TEC slows down the degree of inhibition. Carbon emissions from fertilizers promote the improvement of agricultural TFP by promoting TEC, while its inhibition on TP weakens the promotion.

\section{Discussion and Conclusions}

This paper explores the relationship between climate change and the transformation of agricultural development mode from the perspective of carbon emissions and agricultural 
total factor productivity. Based on the Regional Panel Data of China from 1995 to 2016, the long-term cointegration model and error correction model of agricultural carbon emission and agricultural total factor productivity are constructed. Three conclusions can be drawn:(1) There is a long-term equilibrium relationship between the carbon emissions of pesticide, chemical fertilizer, agricultural irrigation, diesel and agricultural TFP. Agricultural carbon emissions, agricultural diesel emissions and agricultural irrigation carbon emissions will inhibit the growth of agricultural total factor productivity, and the degree of suppression from large to small is irrigation carbon emissions, pesticide carbon emissions and agricultural diesel carbon emissions in turn. Carbon emission from chemical fertilizer will promote the growth of agricultural TFP. (2) Further analysis of the impact mechanism shows that agricultural diesel carbon emissions, agricultural irrigation carbon emissions, pesticide carbon emissions mainly inhibit agricultural TFP by inhibiting TEC, but its promotion on agricultural TP has slowed down the degree of inhibition. Increased carbon emissions from chemical fertilizers will promote the growth of agricultural TFP by increasing TEC, but its negative effect on TP will reduce the degree of promotion. It is consistent with the conclusion of Wang et al. (2019), they believe that the increase of carbon emission intensity will lead to the decrease of the growth rate of green TFP through the expansion of the ineffective rate of production technology. In this article, the impact of the carbon source on the TFP was discussed in detail. (3)Through the error correction model, it can be found that there is a short-term reverse correction mechanism between carbon emission from each carbon source and agricultural TFP, TP,TEC which will recover faster after short-term deviation. In the short term, agricultural membrane carbon emissions, agricultural diesel emissions, agricultural irrigation carbon emissions, and pesticide carbon emissions will inhibit agricultural TFP by suppressing agricultural TEC, while its promotion on agricultural TP has slowed down the degree of suppression. The carbon emission of agricultural machinery will inhibit the agricultural TFP by restraining TP, while it will slow down the degree of suppression to the improvement of TEC. The carbon emission of chemical fertilizer will promote the improvement of agricultural TFP by promoting the improvement of TEC, while its suppression on TP weakens the role of promotion.

Acknowledgments: ALL this, as well as the results of this study, would not have been possible without the moral and administrative support of my colleagues from School of Economics \& Management Northwest University.

\section{References}

Brümmer, B., Glauben, T., \& Lu, W. (2006). Policy Reform and Productivity Change in Chinese Agriculture: A Distance Function Approach. Journal of Development Economics, 81(1), 61-79. https://doi.org/10.1016/j.jdeveco.2005.04.009

Coelli, T., \& Rao, D. S. (2003). Total Factor Productivity Growth in Agriculture: A Malmquist Index Analysis of 93 Countries, 1980-2000. Agricultural Economics, 32, 115-134. https://doi.org/ 10.1111/j.01695150.2004.00018.x

Charnes, A., Cooper, W., \& Rhodes, E. (1978). Measuring the efficiency of decision making units. European Journal of Operational Research, 2, 429-444. https://doi.org/10.1016/0377-2217(78)90138-8

Chen, M., Ma, L., Che, X., \& Dou, H. (2020). Identification of Transformation Stages and Evolution of Agricultural Development Types Based on Total Factor Productivity Analysis: A Case Study of Gansu Province, China. Agriculture, 10(8), 363. https://doi.org/10.3390/agriculture10080363 
Färe, R., Grosskopf, S., Norris, M., \& Zhang, Z. (1994). Productivity Growth, Technical Progress, and Efficiency Change in Industrialized Countries. The American Economic Review, 84, 66-83.

Farrell, M. J. (1957). The Measurement of Productive Efficiency. Journal of the Royal Statistical Society. Series A (General), 120(3), 253-290. https://www.jstor.org/stable/2343100

Huang, Z., \& Mi, S. (2011). Research on Agricultural Carbon Footprint -- Taking Zhejiang Province as an Example. Issues in Agricultural Economy, 32(11), 40-47,111. https://doi.org/10.13246/j.cnki.iae.2011.11.007

Huilong, M., \& Lei, L. (2018). Analysis on the transformation of agricultural economic development mode of BINGTUAN based on TFP. Journal of Agricultural Sciences, 39(3), 33-37. https://doi.org/10.13907/j.cnki.nykxyj.20180925.004

Institute of Resource, Ecosystem and Environment of Agriculture in Nanjing Agricultural University (IREEA). (2016). http://ireea.njau.edu.cn.

Intergovernmental Panel on Climate Change (IPCC). (2006). IPCC Guidelines for National Greenhouse Gas Inventories. www.ipcc-ggip.iges.

Jin, H., \& Kan L. (2013). Measurement and Influential Factors Analysis of China's Agricultural Total Factor Productivity. Agriculture, Farmers and Countryside Journal of Northwest Sci Tech University of Agriculture and Forestry, 13(2), 29-35. https://doi.org/10.13968/j.cnki.1009-9107.2013.02.021

Kumbhakar, S. C., \& Lovell, C. (2000). Stochastic Frontier Analysis: Frontmatter. Cambridge University Press https://doi.org/10.1017/CBO9781139174411

Li, B., Zhang J., \& Li H. (2011). Spatio-temporal characteristics of agricultural carbon emissions and decomposition of influencing factors in China. China Population Resources and Environment, 21(8), 80-86. http://refhub.elsevier.com/S0959-6526(17)31007-7/sref12

Liu, L., \& Zhang, W. (2017). China's agricultural TFP growth and spatial spillover effect: An Empirical Analysis Based on the data of 31 provinces and cities from 2000 to 2014. Western Forum, 27(6), 49-57.

Liu, S., Zhang, S., He, X., \& Li, J. (2016). Efficiency change in North-East China agricultural sector: A DEA approach. Agricultural Economics, 61, 522-532. https://doi.org/10.17221/233/2014-AGRICECON

Mead, R W. (2003). A revisionist view of Chinese agricultural productivity? Contemporary Economic Policy, 21(1), 117-131. https://doi.org/10.1093/cep/21.1.117

Oak Ridge National Laboratory. (2016). https://www.ornl.gov.

Pan Dan. (2014). Calculation of China's Agricultural Green Productivity and Analysis of Influencing Factors Based on Resource and Environment Constraints. Statistics \& Information Forum, 29(8), 27-33. https://chn.oversea.cnki.net/kcms/detail/detail.aspx?FileName=TJLT201408005\&DbName=CJFQ2014

Solow, R. M. (1957). Technical Change and the Aggregate Production Function. The Review of Economics and Statistics, 39(3), 312-320. https://www.jstor.org/stable/1926047

Schultz, T. W., \& Abramovitz, M. (1956). Resources and Output Trends in the United States since 1870. Journal of the American Statistical Association, 52, 281. https://www.jstor.org/stable/2280866

Tone, K. (2002). A slacks-based measure of super-efficiency in data envelopment analysis. European Journal of Operational Research, 143, 32-41. https://doi.org/10.1016/S0377-2217(01)00324-1

Wang, L., Yao H., \& Han X. (2019). Carbon emission, green total factor productivity and agricultural economic growth. Inquiry into Economic Issues, (2), 142-149. https://chn.oversea.cnki.net/kcms/detail/detail.aspx?FileName=JJWS201902019\&DbName=CJFQ2019

Wen, J. G. (1993). Total Factor Productivity Change in China's Farming Sector: 1952-1989. Economic Development and Cultural Change, 42(1), 1-42. https://doi.org/10.1086/452063

West, T. O., \& Marland, G. (2002). A synthesis of carbon sequestration, carbon emissions, and net carbon flux in agriculture: comparing tillage practices in the United States. Agriculture, Ecosystems \& Environment, 91(1-3), 217-232. http://refhub.elsevier.com/S0959-6526(17)31007-7/sref36

Xu, G., \& Song D. (2010). An empirical study on the Kuznets curve of China's carbon emission environment based on Provincial Panel Data. China Industrial Economics, (5), 37-47. https://doi.org/10.19581/j.cnki.ciejournal.2010.05.005

Zhan, J., Xu, Y., Ge, J. (2019). Changes in China's agricultural green productivity considering the cost of carbon emissions. Resources Science, 41(5), 884-896.

https://chn.oversea.cnki.net/kcms/detail/detail.aspx?FileName=ZRZY201905006\&DbName=CJFQ2019

Zhang, B., Xu, K., \& Chen T. (2014). Research on influence of technological progress on carbon dioxide emission intensity. Resources Science, 36(3), 567-576.

https://chn.oversea.cnki.net/kcms/detail/detail.aspx?FileName=ZRZY201403016\&DbName=CJFQ2014 
Zhong, Z., \& Jiang, L. (2019). Impact of Climate Change on Agricultural Total Factor Productivity Based on Spatial Panel Data Model: Evidence from China. Sustainability, 11(6), 1516. https://doi.org/10.3390/su11061516

Zhao, A., \& Li, D. (2011). Cointegration and Cause-Effect Analysis of Carbon Emissions and Economic Growth in China. Resources and Environment in the Yangtze Basin, 20(11), 1297-1303.

https://chn.oversea.cnki.net/kcms/detail/detail.aspx?FileName=CJLY201111002\&DbName=CJFQ2011 